\title{
Research on the New Technique of Paper-cut Art based on Decoration Pattern and Design Ideas of Contemporary Art
}

\author{
Yan Tang ${ }^{1}$ \\ ${ }^{1}$ Art Institute of Jiujiang University, \\ JiuJiang,Jiangxi, 332005 China
}

\begin{abstract}
In this paper, we do research on the new technique of paper-cut art based on decoration pattern and design ideas of contemporary art. Generalized paper-cut is using the cut tool on thin brittle materials of hollow out modelling and in narrow sense paper-cut is to use scissors or a knife carving on paper and pure paper-cut is hollow-out patterns on the paper with scissors. Paper-cut of the aesthetic feeling is done through its form and the form and contains the certain content and the paper-cut works directly describe the object of the subject. Through the analysis and research in this paper, we believe that paper-cut art will develop fast in the near future.
\end{abstract}

Keywords: Paper-cut Art; Decoration Pattern; Contemporary Art; New Methodology.

\section{Introduction}

Folk paper-cut is one of colorful folk arts gardens, its indomitable vitality is rooted in the vast rural towns, handed down from generation to generation, and, after thousands of years, has always maintained the cultural heritage of the Chinese nation ancient, flashing the radiance of the ancient primitive civilization, it combines practical, aesthetic and research value in one, become affect one of the most widespread form of folk art in China. Generalized paper-cut is using the cut tool on thin brittle materials of hollow out modelling and in narrow sense paper-cut is to use scissors or a knife carving on paper and pure paper-cut is hollow-out patterns on the paper with scissors. Some researchers believe that the folk paper-cut is the result of human clothing system, is the adornment of the ancients will dress her after transplantation into Windows evolved gradually, has spread around in the northwest of embroidery patterns to support its origin relationship between. Paper-cutting as an art form has its own unique creation rules, the modelling of this rule is subject to certain ideas, and this kind of idea by the author's ethnic, geographical, historical and cultural traditions, philosophical ideas and life factors such as production, emotional temperament and aesthetic decisions. The folk paper-cut is independent of the western traditional modeling ideas and traditional Chinese with line model system of the third kind of plastic arts, is subjective traditional imagery. The Chinese people have always paying attention to nature and humanity which emphasizes the harmony of man and nature, while western emphasize the difference between human and nature contradiction; China heavy subject, emphasizing the morality, western heavy object, emphasize knowledge and science. Performance in art is closely related to Chinese art and good, and ethics of western art and truth, and closely related to science, so the Chinese art emphasizes lyrical, freehand brushwork in traditional Chinese painting, heavy, speak artistic conception; Emphasis on imitation of western art, realistic, heavy and typical which holds significant meanings and intuitions [1].

Chinese folk art originated in the human to the fear and worship of nature, and human, human and nature harmonious coexistence of historical testimony. Chinese folk art with all the visual arts belong to a part of the Chinese nation culture, and learn from each other, and combine the integral relationship. Folk art in a flexible and optional folk wisdom to show the vitality of 
primitive simplicity, frankness, for thousands of years, as the wisdom of the masses of working people enjoying themselves, always parallel with other arts, complement each other. Any contents that works of art to through certain means of organization structure and performance to appreciate works of art. The organizational structure, performance means is in the form of works of art. Paper-cut of the aesthetic feeling is done through its form, the form and contains the certain content and the paper-cut works directly describe the object of the subject of paper-cut such as the tiger is a folk paper-cut artist's favorite object. Because the tiger is the king of beasts, can hold cardiac demoralizing, eats ghost, draw a tiger in the door [2]. The tiger is ever-victorious generals of folk art. Therefore, we research on the new technique of paper-cut art based on decoration pattern and design ideas of contemporary art in this paper. The figure one is the example of traditional paper-cut.
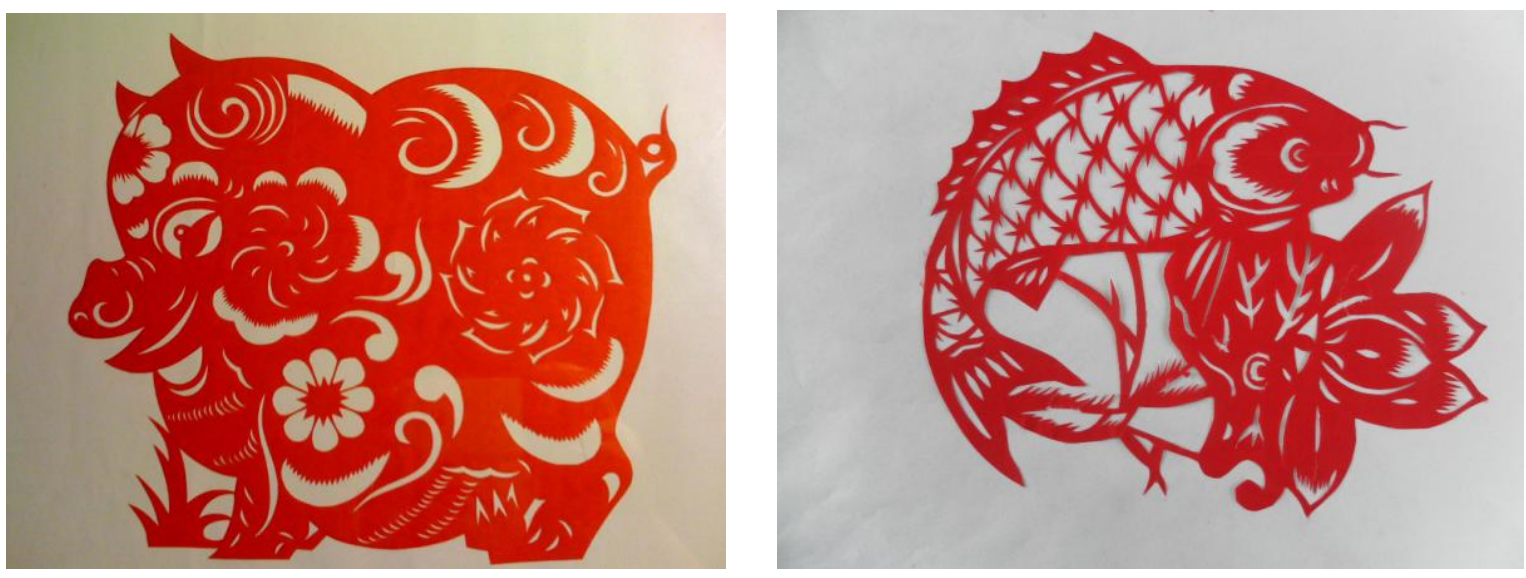

Fig. 1The Example of Traditional Paper-cut

\section{The Proposed Methodology}

The Design Ideas of Contemporary Art. Paper-cut culture is one of China's folk culture and folk art carriers. It has inherited thousands of years of traditional folk culture. Paper-cut culture has a long history, unique style, it is has a strong tradition of Oriental culture, and has a strong rural culture atmosphere. Either from the material of paper cutting, and modelling characteristic, it fully embodies the Chinese traditional folk custom culture. Different geographical characteristics have different paper-cut culture characteristic, the paper-cut culture is reflected in the north of the northerners have humanistic qualities, northerners coarse ore but do not break detail; The southern paper-cut culture reflects the southerners choiceness exquisite and unique. As one of the intangible cultural heritage, it not only has inherited some folk custom and characteristic, it also has a greater contribution on literary world. In the thousands of years ago, people of paper cutting has a wealth of feeling and rely on. Big red is one of the most commonly used color folk paper-cut art, usually in every year holiday period, people use scissors, knives cut out a variety of designs, of course, as one of the features of the Chinese New Year, fish this Mosaic of paper-cut is essential; Will also cooperate with some pattern of flowers, birds, plants. In folk culture also contains numerous verses of paper-cut art, these poems first expressed poets of paper-cut art to appreciate; Actually also suggests that in the past, paper-cut is ubiquitous in people life, people are emotional dependence on things, because after all, poetry is belong to a form of expression of inner world. After many years of design evolution and accumulation, the paper-cut art on the basis of the traditional pattern with many changes in the development, on the kinds of design more rich, added the portrait, Peking 
Opera mask, new content, such as natural landscape at the same time, the design also and social practical and significant events closely, can well reflect the social dynamics and the life of the people. Work mentality and concept design style is the designer itself, both western abstract art and the Chinese traditional folk arts, has a shock of awakening humanity frankness. This also for the current return of human nature, the harmony of society provides the breach of the inheritance and innovation. The design art development of a country is based on their country's national culture as the background. Chinese folk art is unique, pure Chinese temperament, it is the modern art design inexhaustible, inexhaustible source of inspiration, and modern design idea and technique of expression, and will certainly arouse folk art newborn. Paper-cut forms of diversity, functional language. One of the hollow out is the art of paper-cut art commonly used gimmick. Its various forms and through different plane to the size of the hollow out, for a variety of different degree of finish line change to show the paper-cut art aesthetic temperament and interest, make the person get the beauty. Hollow out design with practical design, it has a whole on wall body area of protection, waters the role of the barrier wall, is the art into life, art and practical application of the full performance, it shows that the influence of Chinese paper-cut of modern art and its use value [3-4].

The Realistic Style and Computer Aided Design. Paper-cut is also as a type of decoration, the earliest has not been the invention of paper, then there has been a paper-cutting in the form of a hollow in the stone, jade and carving decorative pattern on the leather. After the western dynasty paper invention, people began to use paper for paper cutting. As a result of the paper is lightsome and convenient, people chose the material as a way of expression, the use of paper for cutter hollow out people to express the inner things and ideas; Gradually formed the great one of the folk art of paper cutting. Entered the new century, the return of the folk art ideological trend increasingly into the various categories of modern visual art, painting, sculpture, design, animation, etc., are ripping nutrition from folk art, as contained in the folk art of mental qualities, nourish and stimulate new art form, establish both national characteristics and times features, and highly personal appearance style of art. Paper-cut art as a traditional culture characterization of specific patterns, patterns, symbols and graphics, is not only physical, but of knowledge, it is intangible, metaphor, intrinsic, these graphics is a sign of good will. While using the borrowed meaning and send lyrical expression method, the content, the sentiment, Italy, and interest into an organic whole, to the viewer to rich imagination space and long aftertaste, implicative and elegant, contains the Oriental aesthetic thought and aesthetic implication of the basic, is also highly idealized way characteristic of China. But paper-cut as an important part of modelling of folk art, and has not been, people know many research only on the surface of artistic features, rather than to her form of overall structure, cultural connotation and forms of deep mining, so that we in the traditional art form has remained at the superficial stage, cannot be accurately annotation, we should be with a mature mind, further understand and digest the traditional art, nutrient and into a new kind of design art. Traditional folk art in iron wall extrusion and segmentation of digital city, with its the fiercest pursuit of truth, the most simple, let the heart of the busy modern city under the mask of real pure able to breathe the fresh air with free; In the tide of globalization and diversification, with its huge influence on the diversity of form and content, have their own unique fashion. As a loose collection of traditions, there is no single recipe for constructing paper-cut designs. But if we restrict ourselves to a subset of all human-made examples, we begin to see some recurring mathematical features. Computer aided design has been a trend. The figure two shows the example for the novel design pattern. 

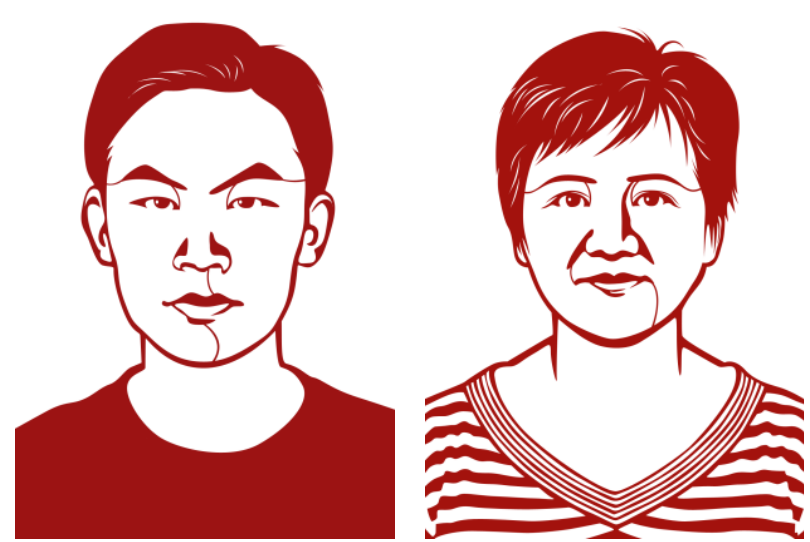

Fig. 2The Example of Recent

The Novel Decoration Pattern. Paper-cut art has created its own unique modelling language and the modelling of paper-cut law is not based on reproduction objective reality, but pay attention to a concept model. This concept with the aid of the connotation of symbol modelling, the paper-cut art on a higher level, is characterized by simple generalization, pure and fresh and pure, adornment sex is strong, the image and the familiar. The creation of paper-cut patterns depend on is a kind of typical primary ways of thinking, this kind of thinking, is a natural without professional training mode of visual perception, embodies the Chinese traditional aesthetic ideal, is full of cognition and conception, and contains the purpose to grasp the overall structure of the object model. Creators with the pursuit of the most essential to the creation, in the heart of creation up without the restrictions of stylized, emotional unconscious naturally and pouring. The utilitarian motivation tends to be easier to close to the essence of beauty. When the feeling of folk paper-cut artist himself into a symbol graphics, not by the moment the stillness of the limit of time and space, also is not bound by visual point of view,
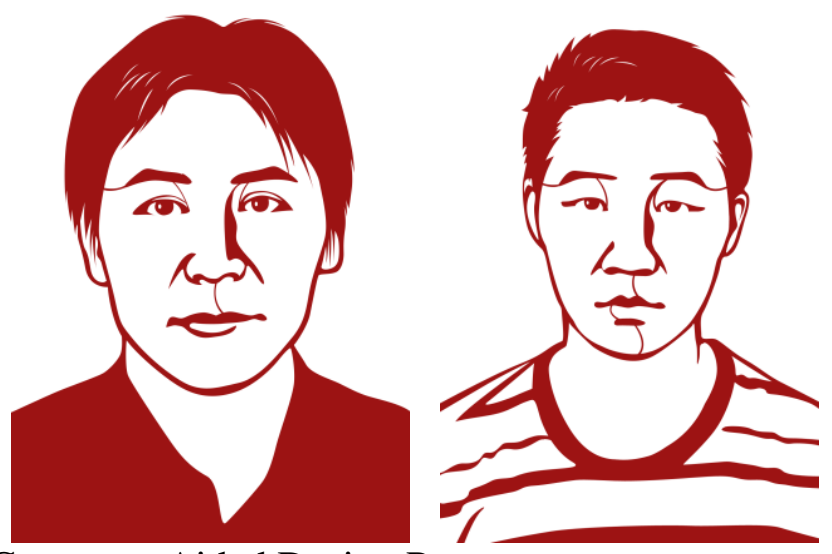

Computer Aided Design Pattern

but according to the authors primary visual perception of an object, according to the intention and inner self ideal, rearranged and construct the real order, and will they materialized into visual forms, the primary visual thinking of infinite freedom, it is the human are not real performance control and interference of the natural scientific knowledge, it breaks the real objects to people made free imagination, beyond the boundaries of the natural and realistic, to create a real deep-themes of art. Paper-cut art as the most widely circulated folk decorative arts in China, with the development of modern art and flourished, slowly into the international stage, became one of the popular fashions of modern art. These folk paper-cut figures have also been integrated into the dress and add special glamour, recently, is often a clothing design competition, clipart from static, flat clothing designer gives the dynamic beauty and three-dimensional beauty, they use clipart ingenious in evening dress, wedding dress, shawl, underwear, would be a perfect show oriental verve. In the following figure three, we show the novel pattern guided paper-cut art. 

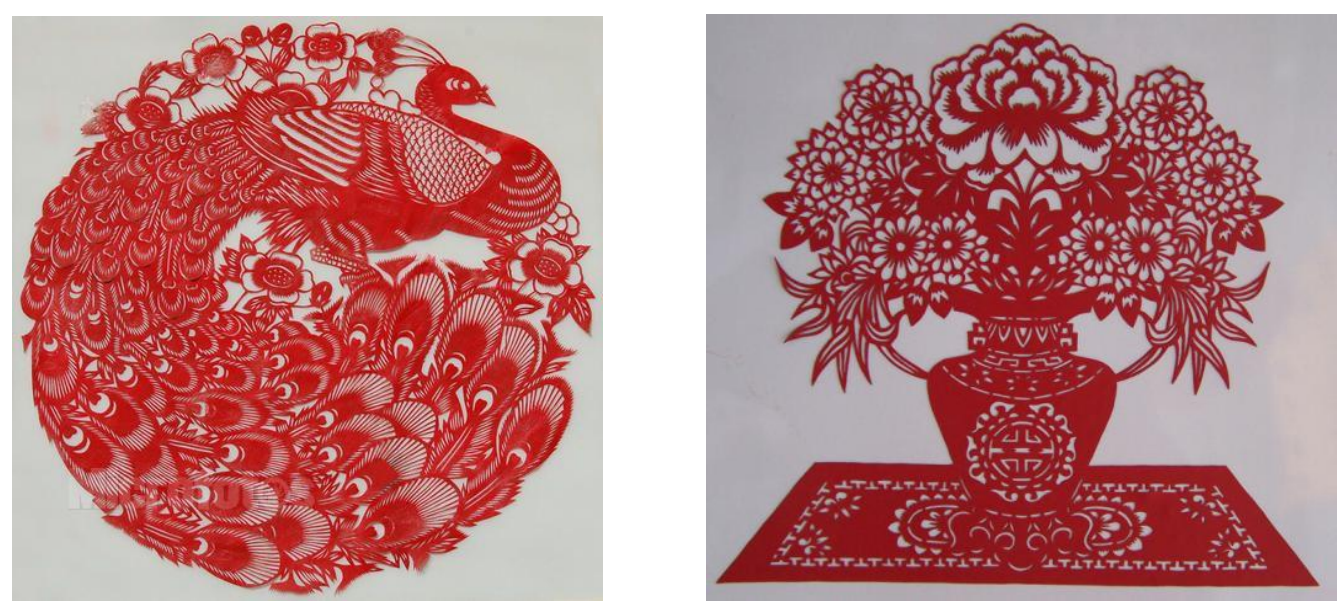

Fig. 3The Example of Novel Pattern Guided Paper-cut Art

\section{Conclusion}

In this paper, we do research on the new technique of paper-cut art based on decoration pattern and design ideas of contemporary art. Paper-cut culture is one of China's folk culture and folk art carriers. It has inherited thousands of years of traditional folk culture. The creation of paper-cut patterns depend on is a kind of typical primary ways of thinking, this kind of thinking which is a natural without professional training mode of visual perception. We firmly believe that the paper-cut art will develop faster and faster in the following time.

\section{References}

[1] Ting, H., Jin, Z., \& Kai-chen, S. (2014). The application of helingeer paper-cut art in packaging design. Packaging Engineering, $35,4,118-122$.

[2] Hui, G., Department, A., \& College, X. N. (2014). China's folk paper-cut art heritage and development. Journal of Anshun University.

[3] Xiu-yun, L., Feng-hu, Y., College, L., \& Unversity, J. N. (2014). Study on characteristics and unique aesthetic merit of paper-cut of man minority in the northeast in comparative perspective-horizon. Jilin Normal University Journal.

[4] Bei G. Analyzing the Application of Silk Clothing Design with Paper-cut Elements[J]. Journal of Zhongyuan University of Technology, 2014. 